\title{
Publisher Correction: The long tail of oncogenic drivers in prostate cancer
}

Joshua Armenia (1D, Stephanie A. M. Wankowicz, David Liu, Jianjiong Gao, Ritika Kundra, Ed Reznik (D), Walid K. Chatila (1), Debyani Chakravarty, G. Celine Han, Ilsa Coleman, Bruce Montgomery, Colin Pritchard, Colm Morrissey, Christopher E. Barbieri, Himisha Beltran, Andrea Sboner, Zafeiris Zafeiriou, Susana Miranda (1), Craig M. Bielski, Alexander V. Penson, Charlotte Tolonen, Franklin W. Huang, Dan Robinson, Yi Mi Wu, Robert Lonigro, Levi A. Garraway, Francesca Demichelis (1D, Philip W. Kantoff, Mary-Ellen Taplin, Wassim Abida, Barry S. Taylor (D), Howard I. Scher, Peter S. Nelson, Johann S. de Bono (D), Mark A. Rubin (D), Charles L. Sawyers, Arul M. Chinnaiyan, PCF/SU2C International Prostate Cancer Dream Team, Nikolaus Schultz and Eliezer M. Van Allen (D)

Correction to: Nature Genetics https://doi.org/10.1038/s41588-018-0078-z, published online 2 April 2018.

In the HTML version of this article, the author group 'PCF/SU2C International Prostate Cancer Dream Team' was duplicated and appeared at the end of the author list but should have appeared only once, in the third-to-last position. In the HTML and PDF versions of the article, the footnote indicating membership for PCF/SU2C International Prostate Cancer Dream Team, 'A list of members and affiliations appears in the Supplementary Note', was missing. The errors have been corrected in the HTML and PDF versions of the article.

Published online: 31 May 2019

https://doi.org/10.1038/s41588-019-0451-6

\section{Publisher Correction: Exome sequencing highlights the role of wild-relative introgression in shaping the adaptive landscape of the wheat genome}

Fei He, Raj Pasam (D), Fan Shi, Surya Kant, Gabriel Keeble-Gagnere, Pippa Kay, Kerrie Forrest, Allan Fritz, Pierre Hucl, Krystalee Wiebe, Ron Knox (D), Richard Cuthbert, Curtis Pozniak D, Alina Akhunova (D), Peter L. Morrell, John P. Davies, Steve R. Webb, German Spangenberg, Ben Hayes (D), Hans Daetwyler, Josquin Tibbits, Matthew Hayden (D) and Eduard Akhunov (D)

Correction to: Nature Genetics https://doi.org/10.1038/s41588-019-0382-2, published online 1 May 2019.

In the version of this article initially published, the top panel of Fig. $5 \mathrm{a}$ contained errors in gene names. 'TaGS5-3A1' at position $\sim 175 \mathrm{Mb}$ should have been 'TaGS5-3A', and 'TaGS5-3A' at position 722 Mb should have been 'TaTGW6-A1'. The errors have been corrected in the HTML and PDF versions of the article.

Published online: 13 June 2019

https://doi.org/10.1038/s41588-019-0463-2 